
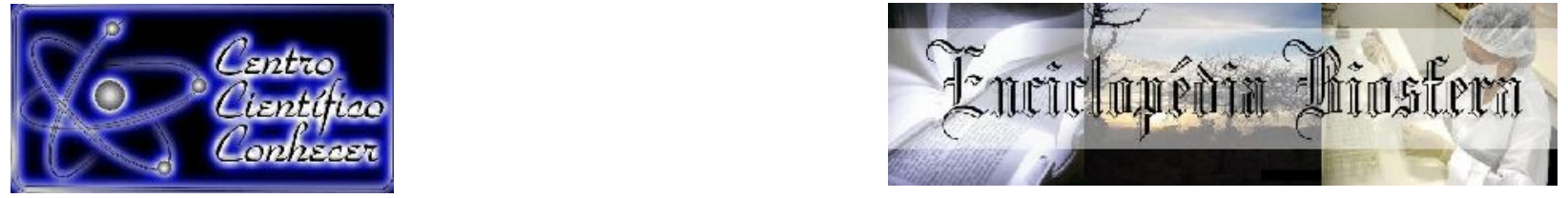

\title{
FORMAÇÃO E RESISTÊNCIA DO BIOFILME MICROBIANO EM INDÚSTRIAS PROCESSADORAS DE ALIMENTOS
}

\section{Ana Carolina Paim Carvalho ${ }^{1}$ Rosanne Aparecida Capanema Ribeiro ${ }^{1}$, Sttephannie Zago $^{1}$, Deborah Santasso Bonnas ${ }^{2}$}

1 Médicas Veterinárias graduandas na Especialização em Controle de Qualidade em Processos Alimentícios (carolveterinaria2011@gmail.com)

1 Professora Doutora do Instituto Federal de Educação, Ciência e Tecnologia do Triângulo Mineiro Campus Uberlândia

Recebido em: 04/10/2019 - Aprovado em: 30/11/2019 - Publicado em: 15/12/2019 DOI: 10.18677/EnciBio_2019B31

Um alimento quando submetido a um processamento deve-se apresentar inócuo e seguro quando destinado ao consumidor final. A contaminação seja por qualquer tipo (física, química ou biológica) pode ocasionar enfermidades e em alguns casos, até a morte. Quando falamos em contaminação biológica podemos citar o biofilme, que se define como uma comunidade microbiológica complexa no qual o microrganismo consegue resistir com maior eficiência a ambientes adversos, principalmente quando relacionada a limpeza e sanitização. Os equipamentos utilizados em indústrias alimentícias têm predisposição a grande contaminação principalmente quando higienizados de forma inadequada o que propicia 0 desenvolvimento de microrganismos patogênicos podendo contaminar o produto final. Sua formação se dá por meio de cinco etapas principais: adesão inicial, adesão irreversível, formação da arquitetura do biofilme, amadurecimento e desprendimento e formação de novo biofilme. Depois de formado sua eliminação se torna mais complicado e difícil, assim o ideal é impedir seu surgimento sendo essencial a verificação e o monitoramento das condições higiênico-sanitários de equipamentos e utensílios utilizados no processamento. Portanto, se faz necessário a implantação dos programas de autocontrole como: Boas Práticas de Fabricação (BPF); Procedimento Padrão de Higiene Operacional (PPHO) e até mesmo Análises de Perigos e Pontos Críticos de Controle (APPCC) afim de prevenir o acúmulo de células microbianas ou biofilmes nas superfícies.

PALAVRAS-CHAVE: Alimento; Biofilme; Inócuo; Patogênicos.

\section{MICROBIAN BIOFILME TRAINING AND RESISTENCE IN FOOD PORCESSING INDUSTRIES}

\begin{abstract}
A food when processed must be safe and safe when intended for the final consumer. Contamination by any kind (physical, chemical or biological) can cause illness and in some cases even death. When we talk about biological contamination we can mention the biofilm, which is defined as a complex microbiological community in which the microorganism can more effectively resist adverse environments,
\end{abstract}


especially when related to cleaning and sanitation. Equipment used in food industries is predisposed to major contamination especially when improperly sanitized, which enables the development of pathogenic microorganisms that may contaminate the final product. Its formation occurs through five main stages: initial adhesion, irreversible adhesion, formation of the biofilm architecture, maturation and detachment and formation of a new biofilm. Once formed, its elimination becomes more complicated and difficult, so the ideal is to prevent its emergence, being essential to check and monitor the sanitary conditions of equipment and utensils used in processing. Therefore, it is necessary to implement self-control programs such as: Good Manufacturing Practices (GMP); Standard Operating Hygiene Procedure (PPHO) and even Hazard Analysis and Critical Control Points (HACCP) to prevent the accumulation of microbial cells or biofilms on surfaces.

KEYWORDS: Food; Biofilm; Safe; Pathogenic.

\section{INTRODUÇÃO}

A qualidade dos alimentos quando se trata de aspecto microbiológico se tornou de suma importância, pois quando os mesmos estão contaminados o prejuízo a saúde das pessoas é imenso, sendo capazes de provocar diversas enfermidades e em certos casos, até a morte. Devido a isso, há grande preocupação com o fato de a contaminação microbiológica ocorrer em qualquer ponto na cadeia produtiva, em especial quando as bactérias se encontram em forma diferente da planctônica, de maneira organizada em comunidade com diferentes graus de complexidade, aderidas a superfícies, onde são reconhecidas como biofilme (BRIDIER et al., 2015).

Conforme descrito no Codex Alimentarius (2019), o consumidor em geral tem direito de adquirir um alimento seguro e inócuo. A qualidade e a segurança na alimentação constituem um direito em todo o mundo. Com isso, as empresas produtoras de alimentos cada dia vem buscando mais, assegurar a qualidade dos seus produtos e serviços já que os consumidores estão mais preocupados com a qualidade do que consome.

O biofilme bacteriano é um tipo especial de crescimento, onde os microrganismos conseguem resistir com maior eficiência a ambientes adversos a sua existência como estresses ambientais tais como: limpeza, desinfecção e inibição. Além disso, levam a persistência de microrganismos patogênicas e são grandes responsáveis por contaminação cruzada recorrente em produtos alimentícios. Conforme estudo, a maioria dos microrganismos são capazes desenvolver o processo de formação de biofilme, isso leva a uma grande preocupação com a segurança dos alimentos (MIAO et al., 2017).

Os principais microrganismos capazes de desenvolver o processo de formação de biofilme podem gerar problemas relacionados a contaminação e saúde pública, os principais são: Enterococcus faecium, Pseudomonas aeruginosa, Micrococcus sp., Pseudomonas fragi e Pseudomonas fluorescens. Como exemplos de patógenos: Staphylococcus aureus, Yersinia enterocolitica, Salmonella Typhimurium, Escherichia coli O157:H7, Listeria monocytogenes e Bacillus cereus (GOMES, 2016).

Os equipamentos nas indústrias de alimentos estão predispostos a grande contaminação por bactérias devido a matéria-prima orgânica conter elevada quantidade de proteínas e substratos para microrganismos e quando não são devidamente limpas, permitem o desenvolvimento de microrganismos e até o desenvolvimento de biofilme, o que pode contaminar o produto final (MÜCKE, 2016). 
Quanto aos efeitos prejudiciais, segundo Caixeta (2008) são inúmeros na indústria alimentícia, quando o microrganismo se aderem de forma irreversível a superfície de um equipamento ou instalação o resultado são graves problemas, pois o biofilme tem a capacidade de se tornar fonte crônica de contaminação causando grandes perdas no produto, além de ocasionar prejuízos financeiros à indústria, em virtude da diminuição da vida-de-prateleira dos produtos alimentícios.

Também as indústrias, especialmente as do setor de alimentos, precisam se precaver para impedir o acúmulo de partículas e células microbianas na superfície de equipamentos e a subsequente formação de biofilme. Sabendo que a remoção de biofilmes é um processo difícil e trabalhoso, um programa de auto controle (Procedimento Padrão de Higiene Operacional) deveria ser desenvolvido para qualquer indústria do ramo (BRIDIER et al., 2015).

Mediante a isso, a prevenção do processo de formação do biofilme por meio de medidas que inibam ou diminuam a adesão bacteriana, controle físico e químico, indução de descolamento do biofilme, bloqueio de regulação do biofilme, entre outros. No entanto, várias estratégias de controle de biofilme já foram apresentadas, mas esse obstáculo ainda permanece sem solução eficiente, demonstrando a grande importância de estudos relacionados ao tema (GUTIÉRREZ et al., 2016).

Diante do exposto, o objetivo do presente trabalho é reunir contextos diferentes em uma revisão bibliográfica, de forma a explorar a importância e os impactos da formação de biofilmes nas indústrias de alimentos, utilizando como base, as principais bibliografias encontradas acerca do assunto para fundamentar a pesquisa sobre os impactos acarretados pela formação dos biofilmes microbianos nas indústrias de alimentos.

\section{Biofilmes: Conceito, Estrutura e Composição}

Biofilme tem como definição um ecossistema ou comunidade microbiológica complexa, que tem como característica células irreversíveis que possui adesão a um substrato ou podendo estar aderida entre si e colocadas em uma matriz formada de polissacarídeos extracelular de produção própria (CAIXETA, 2008; SALDANHA, 2013). Já Brasão (2017) caracteriza os biofilmes como agrupamentos estruturais organizados de bactérias aderidas umas nas outras, geralmente mais que dois tipos de microrganismos, por uma matriz extracelular.

A composição da matriz do biofilme tem como parte mais significativa a água com variação entre 70 a $97 \%$ da sua totalidade. Já o microrganismo propriamente dito representa somente uma pequena parte, frequentemente 2 a $5 \%$ da matriz do biofilme (CASALINI, 2008).

A matriz de substâncias poliméricas extracelulares de origem microbiana é responsável pela morfologia, estrutura, coesão e integridade funcional do biofilme. Ainda que haja a predominância de polissacarídeos em sua composição, estes também pode ser constituída por proteínas, como glicoproteínas, fosfolipídios e ácidos nucleicos (CASALINI, 2008).

Para maior chance de sobrevivência, mecanismos na sua composição foram sendo desenvolvidos para se adaptar a pressão que o ambiente proporciona, a estratégia de formação de biofilme, permitindo o agrupamento de microrganismos de forma organizada para que assim possam formar uma coesa e robusta comunidade de células com forte comunicação intercelular (GOMES, 2016). 
TABELA 1: Composição do Biofilme

\begin{tabular}{lc}
\hline \multicolumn{1}{c}{ Componente } & $\%$ da matriz \\
\hline Água & Até 97\% \\
\hline Células microbianas (muitas espécies) & $2-5 \%$ \\
\hline Polissacarideos (homo e hetero) & $1-2 \%$ \\
\hline Proteinas (incluindo enzimas) & $<1-2 \%$ \\
\hline DNA e RNA & $<1-2 \%$ \\
\hline lons & Livre \\
\hline
\end{tabular}

FONTE: (CASALINI, 2008).

Os biofilmes podem acarretar vários problemas em diversas áreas, principalmente na alimentícia, já que sua colonização nas superfícies em indústrias pode contaminar produtos, alterando suas características organolépticas, além de possibilitar diversas doenças transmitidas por alimentos (DTA) (GOMES, 2016). Quando as bactérias conseguem a formação de biofilme, seu metabolismo se altera e a comunicação célula com célula fica em maior sintonia, ainda conseguem evadir a resposta de sanitizantes e produtos químicos (SINGH et al., 2014).

A forma mais comum de biofilme na natureza se dá pela composição de duas ou mais espécies bacterianas (BHARDWAJ et al., 2014). Depois de colonizarem, elas podem diminuir ou aumentar a diversidade de um biofilme, por diversos fatores como nutrientes, metabólicos nocivos entre outros (IST, 2008).

Com formato de cogumelo ou pilares cilíndricos é possível uma maior absorção de nutrientes do ambiente e o mínimo de desperdício, sustentando toda a estrutura do biofilme. (CLUTTERBUCK et al., 2007).

A matriz expolissacarídica também é responsável por manter as células bem próximas quando estão na estrutura biofilme, realizando fortes interações intercelulares chamadas de "quorum sensing" (QS), que pode ser entendido como "sentido de grupo", ou seja, as células se comunicam entre si por meio de moléculas químicas, exibindo um modelo de vida organizado, onde se estabelecem atividades coordenadas (FLEMMING; WINGENDER, 2010).

As "quorum sensing" (QS), apresentam uma gama de funções que ajudam na proteção dos microrganismos quando o mesmo se encontra na forma de biofilme, esses mecanismos ajudam na maior resistência e na sobrevivência (BHARDWAJ et al. 2014). 


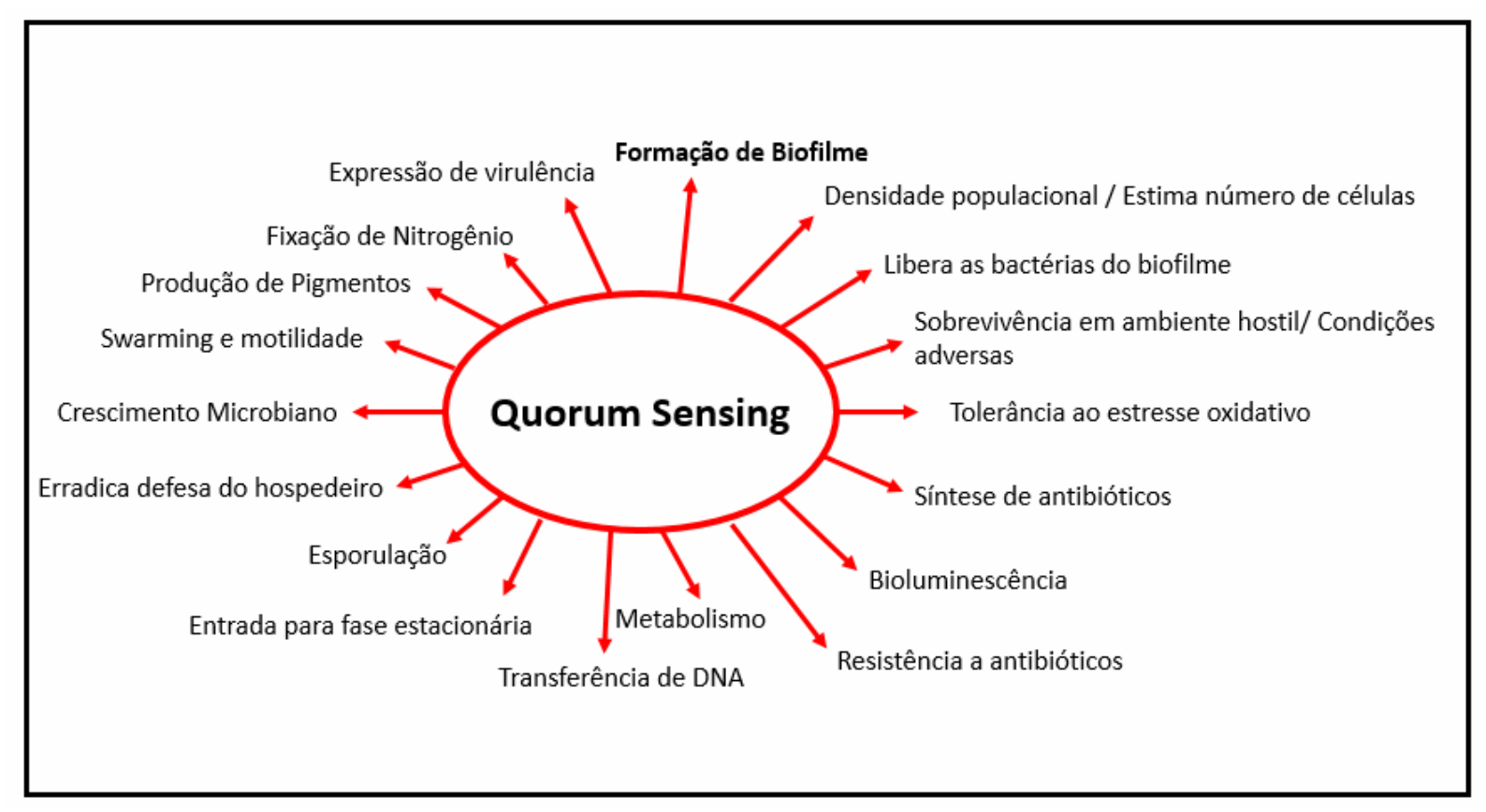

FIGURA 1: Resumo da gama de funções do Quorum Sensing FONTE: Adaptação de BHARDWAJ et al. (2014).

A bactéria pode ser encontrada em dois estados no ambiente, planctônica (flutuante) para proliferação ou séssil (imóvel) para persistência. Os microrganismos sésseis constituem o biofilme através da produção da matriz com polímero orgânico e hidratado. Esse artificio tem como objetivo a defesa contra adversidades provindas do ambiente externo (alteração de $\mathrm{pH}$, temperatura, nutrientes, ação de agentes físicos e químicos), de resposta imune inata e adquirida e da ação de antibióticos dentro do organismo (CLUTTERBUCK et al., 2007).

\section{Biofilmes nas indústrias: Etapas de formação}

Os biofilmes são uma estratégia de proteção de crescimento dos microrganismos, assim, se tornam cerca de dez até mil vezes mais resistentes, dificultando assim seu controle em áreas industriais (YORK, 2017). Com a automatização dos processos industriais, os alimentos passaram a entrar em contato mais vezes com as superfícies dos equipamentos, ampliando as chances de transferência de patógenos para o meio e propiciando a formação de biofilmes (WANG et al., 2014).

A formação e acúmulo do biofilme se dá em qualquer superfície que tenha variedade de substrato o qual é necessário para seu desenvolvimento, na indústria de alimento pode-se destacar: aço inox, vidro, polipropileno, fórmica, ferro, poliestileno de baixa densidade, policarbonato, entre outros. $O$ calor provoca a cristalização do biofilme, o que geralmente causa crostas que são muito aderidas nas superfícies, isso protege ainda mais os microrganismos e dificultando ainda mais os procedimentos de higiene (JAHID; HA, 2012).

Nas indústrias alimentícias, o desenvolvimento de biofilmes além de provocar perdas econômicas, uma vez que a contaminação dos alimentos reduz o tempo de 
prateleira, gera descartes e gastos com sua eliminação. Quando organizadas nessa forma séssil, as bactérias adquirem uma resistência superior à sanitizantes, o que leva a utilização de altas concentrações de produtos químicos, em curtos intervalos de tempo, que podem resultar em corrosão acelerada dos maquinários, interrupção na produção para higienização do ambiente e aumento na jornada de trabalho dos funcionários (BRASÃO, 2017).

Os biofilmes concedem aos microrganismos além de uma elevada resistência a vários fatores estressantes do meio, uma alta capacidade adesiva em diversas superfícies abióticas como aço inoxidável, plástico e lona, que são amplamente utilizados nas indústrias processadoras de alimentos (KUMARI; SARKAR, 2016; MAJED et al., 2016).

A aderência de microrganismos a superfícies de processamento de alimentos ocorre de maneira rápida (usualmente entre 5 e 30 segundos), e em razão disso frequentemente a higienização das superfícies não é o bastante para impedir que essa adesão ocorra. A adesão é influenciada tanto por características superficiais como hidrofobicidade e morfologia, quanto por características do meio como temperatura e $\mathrm{pH}$ e particularidades dos próprios microrganismos como a presença de flagelos (TEIXEIRA et al., 2015).

O biofilme tem sua formação descrita de forma didática em cinco etapas distintas: A primeira se dá pela adesão inicial no qual a mesma pode ser revertida, seguindo, a segunda etapa se dá pela adesão irreversível como o próprio nome já diz não e possível reverter a partir desta, a terceira etapa se tem a formação do esqueleto, ou seja, da arquitetura do biofilme, nesta fase ele começa a ganhar forma seguido do seu amadurecimento, na quarta etapa podendo então, sofrer o desprendimento e então iniciar novamente todo o ciclo com a formação de um novo biofilme (LASA et al., 2006; CAPELLETTI, 2016).

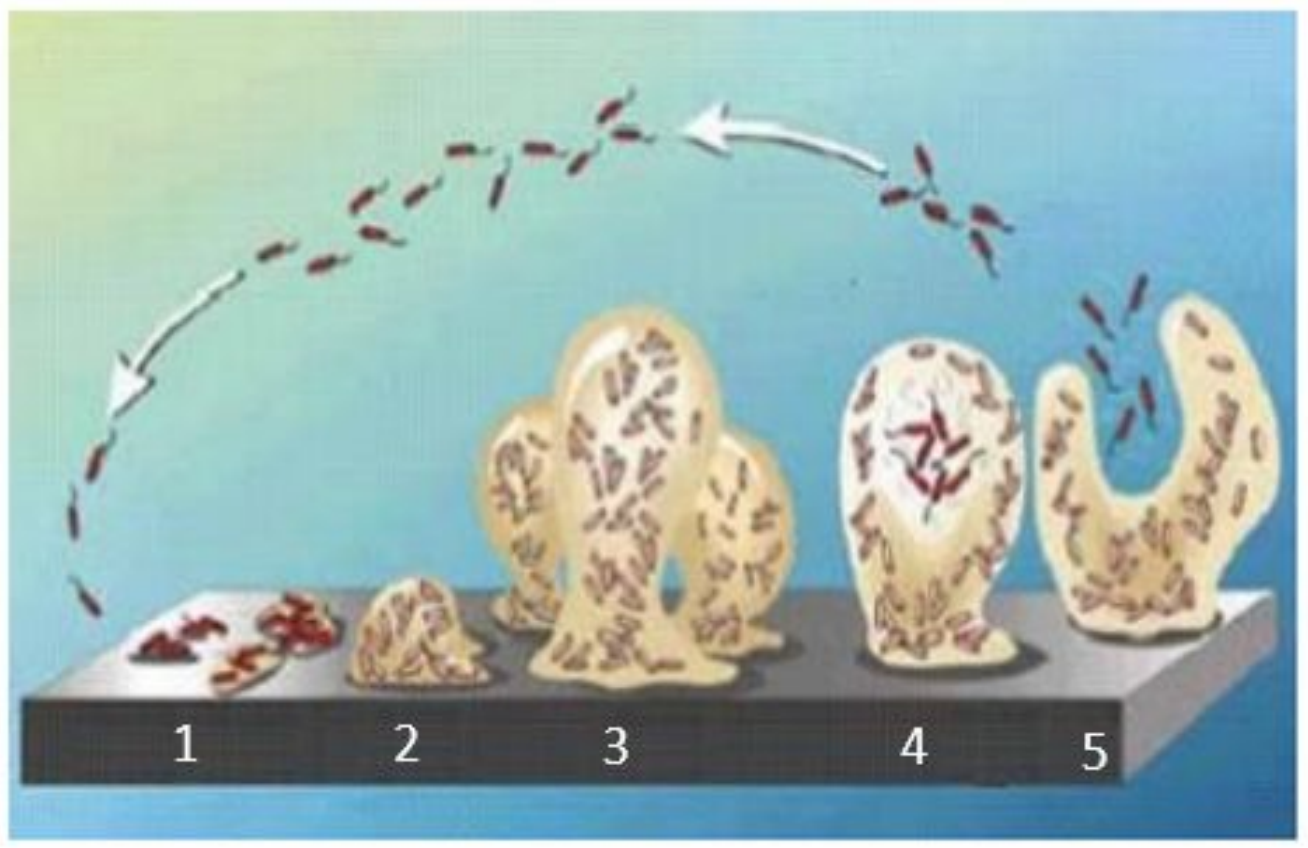

FIGURA 2: Cinco etapas da formação do biofilme. 1- Adesão inicial; 2- Adesão irreversível; 3- Formação do esqueleto/arquitetura; 4Amadrecimento e 5- Desprendimento com início de novo ciclo com a formação de um mais biofilme. FONTE: CAPELLETTI (2016). 
A formação do biofilme se inicia com a absorção de moléculas orgânicas, vindas dos próprios alimentos manipulados nas superfícies como proteínas e carboidratos, e de moléculas inorgânicas, compondo um filme condicionante. Subsequentemente bactérias se aproximam e aderem ao filme, formando comunidades que podem suportar a ação de agentes químicos e se multiplicar (TONDO, 2019). A fase inicial a adesão pode ser revertida, pois os microrganismos ainda não sofreram modificações que sucedem a formação do biofilme, podendo retornar ao seu estilo de vida anterior (CAPELLETTI, 2016).

Já a segunda etapa, tem-se a formação da adesão irreversível que se dá pela interação inicial fraca da bactéria com o substrato, resulta do ancoramento de apêndices (pili, flagelo, proteínas adesina) e/ou da produção de substâncias poliméricas extracelulares, fazendo com que as ligações entre as células e a superfície se fortaleçam, essa adesão tem ocorrência poucas horas após o contato (LASA et al., 2006). Contudo, de acordo com Oliveira (2010a), há uma elevada probabilidade de que as células aderidas irreversivelmente permaneçam mesmo após a higienização, sendo essa uma das principais razões para a formação de biofilmes em superfícies que entram em contato com alimentos.

Quando se inicia a quarta etapa o desenvolvimento do esqueleto se inicia, ou seja, o biofilme começa a formar sua arquitetura, as microcolônias estão presentes a partir do acumulo e o crescimento dos microrganismos envolvidos pela matriz de polímeros extracelulares (TEIXEIRA et al., 2015).

A formação do biofilme maduro ocorre de três a seis dias após a adesão inicial, podendo chegar a dez dias, assemelha a um recife de coral contendo microcolônias piramidais ou em forma de cogumelo de organismos incorporados dentro de um glicocálix extracelular, com canais e cavidades para permitir a troca de nutrientes e resíduos (OLIVEIRA et al., 2010b).

A fase chamada de dispersão é a última das cinco etapas de formação do biofilme (CAPELLETTI, 2016). Nessa etapa, existem algumas possíveis causas para que ocorra o desprendimento do biofilme como: alterações do ambiente externo, alterações internas do biofilme, podendo citar como principal, a degradação enzimática endógena (TONDO, 2019).

Pode-se citar alguns microrganismos capazes de participar do processo de adesão como: Pseudomonas aeruginosa, Pseudomonas fragi e Pseudomonas flurescens; Micrococcus sp.; Enterococcus faecium, Yersinia enterocolitica; Salmonella Thyphimurium; Escherichia coli; Staphylococcus aureus; Bacillus cereus, Alcaligenas, Flavobasterium e Listeria monocytogenes (CAPELLETTI, 2016).

Dos microrganismos citados acima, a Pseudomonas aeruginosa é considerado um modelo para estudar as etapas de formação de biofilmes, pois é muito resistente a desinfetantes e sanitizantes. É comumente encontrada no meio ambiente, na água, no solo e em várias vegetações ao redor do mundo (LALAWMPUII; CHATLI, 2017).

\section{Higienização na indústria alimentar}

Para um produto seguro e inócuo, além de controlar a presença dos microrganismos no alimento, é essencial verificar e monitorar as condições higiênico-sanitários de equipamentos e utensílios utilizados no processamento. Assim, é necessário um programa efetivo de limpeza e sanitização para inativar 
microrganismos e prevenir o acúmulo de células microbianas ou biofilmes nas superfícies (GARCIA, 2015).

Como já se sabe, toda empresa voltada para o ramo alimentício segue alguns pré-requisitos para obtenção de um alimento inócuo e de qualidade, o manual de Boas Práticas de Fabricação destaca-se pela sua importância e tem como finalidade, alimentos em conformidade com a legislação e seguros para a comercialização. A Resolução da Diretoria Colegiada (RDC) no 216 de 15 de setembro de 2004, estabelece os procedimentos que devem ser adotados para os serviços de alimentação, de forma a garantir a preparação de alimentos em condições higiênicos sanitárias adequadas (SOUZA et al., 2014).

Nas empresas voltadas para produção de alimentos a aplicação regular de procedimento de limpeza e desinfecção, sempre foi a melhor estratégia utilizada para controlar a instalação de microrganismos patogênicos e deterioradores em equipamentos industriais ou nos próprios produtos. No entanto, muitas vezes, os biofilmes possuem resistência contra processos de sanitização, que são fatais às células livres, e por isto precisa-se garantir a adoção de um programa de higienização efetivo para prevenir a adesão de células plactônicas a superfícies (JAHID; HA, 2012; BRASÃO, 2017).

Os locais mais propícios à formação de biofilmes são cantos, juntas, articulações, fendas em tubagens ou sistemas de tubagem sem saída. Para que esses organismos capazes de formar biofilme possam ser removidos de estruturas e equipamentos, a higienização deve ser capaz de penetrar na matriz de exopolissacarídeos e ganhar acesso às células microbianas promovendo a inativação e a remoção do mesmo (SOUZA et al., 2014). Conforme a biomassa do biofilme se desenvolve, mais árdua será sua remoção ou inativação, sendo assim, importante que o sanitizante utilizado consiga reduzir a quantidade de células livres e também prevenir sua adesão (MARTINIS, 2012; MILLEZI et al., 2012).

Define-se sanitizantes ou desinfetantes como formulações que têm na sua composição substâncias microbicidas que apresentam efeito letal sobre microrganismos não esporulados, de acordo com a Agência Nacional de Vigilância Sanitária (ANVISA), através da portaria $n^{\circ}$ 15, de 23 de Agosto de 1988.

Existem alguns sanitizantes que tem seu uso prevalente nas indústrias de alimentos no Brasil, são aqueles que possuem princípios ativos dos grupos: quaternários de amônio, compostos inorgânicos liberadores de cloro ativo, compostos orgânicos liberadores de cloro ativo, compostos químicos à base de ácido peracético, iodo e derivados. A escolha depende do tipo de microrganismo que se espera destruir, assim como material do equipamento (BRASIL,1988). Conforme Srey et al. (2018), cloro, peróxido de hidrogênio, iodo, ozônio e ácido peracético estão entre os principais agentes sanitizantes utilizados na indústria de alimentos.

Pode-se utilizar o sanitizante mais potente, mais não se deve esquecer que alguns elementos podem limitar sua eficiência, diminuindo e removendo sua ação. Material orgânico, pH, temperatura, dureza da água, inibidores químicos, concentração e tempo de contato, também são fatores importantes que influenciam a ação dos sanitizantes (SOUZA et al., 2014).

Um fator que está diretamente relacionado a resistência microbiana é a exposição a concentrações subletais de sanitizantes, que podem despertar mecanismos de defesa nas bactérias em adaptação ao meio, fazendo com que elas consigam conservar-se mesmo em ambientes hostis (PEREIRA, 2014). Mesmo seguindo todos os procedimentos à risca, alguns microrganismos sobre estruturas 
de biofilme conseguem se proteger e, assim, induzir a seleção de fenótipos resistentes (SIMÕES et al., 2010).

Portanto, para que as recomendações de qualidade microbiológica sejam alcançadas, a adoção de programas de auto controle, bem como matéria prima de qualidade e a adoção de práticas higiênico-sanitários por parte dos colaboradores, são fundamentais. Para tanto, a aplicação de ferramentas de controle de qualidade é imprescindível. As Boas Práticas de Fabricação (BPF) e os Procedimentos Padrão de Higiene Operacional (PPHO), que são pré-requisitos do sistema de Análise de Perigos e Pontos Críticos de Controle (APPCC), abordam, dentre outros, os princípios básicos de higiene industrial, como: higiene de instalações, de equipamentos e de utensílios utilizados no preparo de alimentos. Ainda que todas as boas práticas de fabricação sejam praticadas nas indústrias alimentícias, é praticamente inevitável a formação de biofilmes. Assim sendo, torna-se indispensável a realização de análises para identificação dos patógenos para eleição do método mais competente na eliminação de bactérias, assegurando a produção de um alimento seguro ao consumidor (GARCIA, 2015).

\section{Doenças transmitidas por alimentos}

As enfermidades que são transmitidas pelos alimentos recebem o nome de DTA's (Doenças Transmitidas pelos Alimentos) e são em geral um dos maiores problemas de saúde pública mundial. Estas ocorrem quando patógenos contaminam alimentos, podendo não alterar características como sabor, aparência e sabor, mas com carga microbiana capaz de causar danos a saúde dos consumidores (OLIVEIRA 2010a).

As causas principais das enfermidades proveniente dos alimentos vem de toxinas, bactérias, vírus e parasitas. Devido a diversidade e virulência das bactérias, elas constituem o grupo microbiano de maior incidência e relevância em relação a capacidade de causar danos à saúde do homem (SILVA et al., 2017).

A maioria das bactérias causadoras de doenças alimentares tem a capacidade de formação de biofilmes e já foram isolados em indústrias alimentícias. Bravo (2016) identificou biofilmes de Staphylococcus spp. em laticínios produtores de queijo minas frescal no estado de São Paulo em superfícies de aço inoxidável e polipropileno. Este patógeno transmite uma intoxicação alimentar a partir do consumo de alimento contaminado, gerando sintomas como náuseas, vômitos, cólicas, pressão e temperatura baixas (SILVA et al., 2017).

Silva (2017) verificou a distribuição e ocorrência de linhagens e genes específicos relacionados à formação de biofilmes de Bacillus cereus isolados dos diversos estágios da cadeia produtiva de leite e produtos lácteos, concluindo que $98,5 \%$ dos genes foram classificados como moderados produtores de biofilmes. Este microrganismo é um dos agentes mais envolvidos em surtos de toxinfecções alimentares e causa sintomas diarreicos e emético. A patologia pode ser provocada pela ingestão de toxinas secretadas no alimento ou através da ingestão do próprio patógeno presente no alimento, que prolifera no intestino e produz enterotoxinas (EHLING-SCHULZ et al., 2014).

Gonçalves (2017) isolou biofilmes de estirpes persistentes de Listeria monocytogenes com origem em indústrias de carne de suínos e de aves. A listeriose pode ser invasiva, apresentando sintomas cerca de 20 horas após a ingestão do alimento, comuns de patologias gastrointestinais como diarreia, vômito e febre, ou 
não invasiva, uma forma de infecção grave que causa sintomas severos e tem elevada taxa de mortalidade.

Além disso, Reis-Teixeira et al. (2017), avaliaram a formação do biofilme de $L$. monocytogenes em utensílios utilização em indústria alimentícia, observando formação em estruturas de aço inox, mármore, granito, vidro e polipropileno e silestone, observando com isso, crescimento, viabilidade e arquitetura.

Marquezine (2015) verificou a capacidade de estirpes de Salmonella entérica isoladas de aviários e linhas de abates de aves, e dentre as estirpes estudadas todas foram consideras produtoras de biofilme in vitro. Segundo o mesmo autor, as salmoneloses geralmente se iniciam com quadros entéricos agudos ou crônicos, podendo levar a infecções septicêmicas, artrite, osteomielite e etc.

Em virtude da habilidade de muitos microrganismos patogênicos de origem alimentar em fixar-se e formarem biofilmes em superfícies de instalações e equipamentos de processamento de alimentos, a eliminação e prevenção da formação destas estruturas, detém constante atenção nas indústrias alimentícias, mas em consequência de falhas na projeção dos equipamentos para sua total higienização e aumento da resistência das bactérias aos agentes microbianos, ainda há grande dificuldade na aplicação de medidas que sessem este tipo de contaminação (TEIXEIRA et al., 2015).

\section{Detecção de biofilme nas indústrias}

Dentre os diversos métodos para detectar e monitorar a superfície das instalações e equipamentos na indústria de processamento de alimentos, podemos citar duas mais importantes a técnica do swab e o teste de ATP-Bioluminescência (BRIDIER et al., 2015).

Pires et al. (2005), afirmam que a técnica do swab tem sido muito utilizada para coleta de microrganismos que possam ter entrado em contato com a superfície dos alimentos. Esta técnica permite avaliar a qualidade higiênica de superfícies, e tem como vantagem o baixo custo e a fácil utilização.

Já o teste de ATP-Bioluminescência é considerado rápido, pois o resultado é obtido em 5 a 10 minutos após aplicação. Neste teste, a produção de ATP está relacionada com a quantidade de microrganismos e resíduos alimentares que estão presentes. Sua utilização facilita ações corretivas imediatas pela rapidez no resultado. No entanto, o teste de ATP-Bioluminescência não pode ser usado para determinar a contagem microbiológica, mas pode ser um método alternativo e viável para avaliar o procedimento de higienização, já que, indica se a superfície está ou não em condições higiênicas satisfatórias (BRIDIER, et al., 2015).

Algumas bactérias formadoras de biofilme não são possíveis de serem cultivadas, por isso, é necessário lançar mão de ferramentas imunológicas e moleculares para identificar todos os patógenos presentes durante determinados processos e permitir o monitoramento dos biofilmes formados nas indústrias (BRIDIER et al., 2015).

É extremamente importante impedir a contaminação microbiológica dos alimentos, mesmo enquanto a bactéria está em seu estado planctônico, no entanto, quando houve falha nesse processo, prever o potencial estabelecimento de patógenos e sua possível formação em biofilme no ambiente de processamento de alimentos, é interessante, porém, ainda não há métodos capazes de realizar tal tarefa (BRIDIER et al., 2015). 
Ainda não existe um método rápido para a contagem de microrganismos do biofilme para os serviços de alimentação. As técnicas convencionais não permitem a separação quantitativa das bactérias aderidas, mas são capazes de fornecer informações importantes para o controle do crescimento da microflora (PIRES et al. 2005).

\section{CONSIDERAÇÕES FINAIS}

Como forma de se proteger, os microrganismos acabam utilizando dessa estratégia de formação de biofilme, uma vez que, assim conseguem ser mais resistentes a produtos de limpeza e sanitizantes. Assim cresce, a preocupação nas indústrias processadoras de alimentos, por serem causadores de enfermidades ou deterioração propriamente dita do alimento, com alterações das características organolépticas do produto. Desse modo, a implementação dos programas de auto controle se tornam de suma importância, já que a partir deles, será possível o correto procedimento de higienização, diminuindo assim, o risco de formação de biofilme.

Controlar a formação dos biofilmes microbianos tem importância significativa, quando se trata de indústria processadora de alimentos, podendo causar prejuízos econômicos, quanto de saúde da população que o consome.

Entender sobre os aspectos gerais de formação, estrutura, resistência são fundamentais para que ações corretivas possam ser elaboradas e que os programas de auto controle possam ser executados, de modo a abranger todos os aspectos, a fim de eliminar a permanência do biofilme.

Devido à alta resistência dos biofilmes formados por bactérias patogênicas, ao fato desse mecanismo de defesa facilitar a contaminação dos alimentos nas indústrias e as doenças transmitidas por alimentos serem uma importante questão de saúde pública, é necessário, cada vez mais pesquisas sobre bactérias nesse estado, a fim de otimizar os procedimentos de limpeza e desinfecção nas indústrias, além do desenvolvimento de ferramentas de diagnóstico mais eficazes e acessíveis.

\section{REFERÊNCIAS}

BRASÃO, S. C. Biofilmes de Salmonella Minnesota: Formação, influência da superfície, inibição por agentes químicos e importância do período entre tratamentos. Dissertação (mestrado em Ciência e Tecnologia de Alimentos). Universidade de São Paulo. Da superfície, inibição por agente químicos e importância do período entre tratamentos. Dissertação (Mestrado em Ciências Veterinárias). Universidade Federal de Uberlândia, 2017.

BRASIL. Portaria no 15 de 23 de agosto de 1988 da Agência Nacional de Vigilância Sanitária. Determina que o registro de produtos saneantes domissanitários com finalidade antimicrobiana seja procedido de acordo com as normas regulamentares. Diário oficial [da] República Federativa do Brasil, Brasília, DF, 05 set. 1988.

BRAVO, M. Estudo genotípico e fenotípico de Staphylococcus spp. formadores de biofilmes isolados em linha de produção de queijo minas frescal e de leite de vacas com mastite no estado de São Paulo. 2016. Dissertação (mestrado em Ciência e Tecnologia de Alimentos). Universidade de São Paulo. Da superfície, inibição por agente químicos e importância do período entre tratamentos. 
Dissertação (Mestrado em Ciências Veterinárias). Universidade Federal de Uberlândia, Uberlândia, 2017.

BRIDIER A; SANCHEZ-VIZUETE P.; GUILBAUD M; PIARD J. C.; NAIITALI M. et al. Biofilm-associated persistence of food-borne pathogens. Food Microbiology, v. 45, p. 167-178. DOI: 10.1016/j.fm.2014.04.015

BHARDWAJ. A.K.; VINOTHKUMAR. K.; RAJPARA, N. Bacterial Quorum Sensing Inhibitors. Attactive Alternatives for Control of Infectious Pathogens Showing Multiple Drug Resistence. Recent Patents on Anti-Infective Drug Discovery, v. 8, p. 68-83. 2014. Disponível em: https://www.ncbi.nlm.nih.gov/pubmed/23394143.doi?

CAPELLETTI, R. V. Avaliação da atividade de biocidas em biofilmes formados a partir de fluido de corte utilizado na usinagem de metais. 81f. Dissertação (Mestrado em Engenharia Química) - Faculdade de Engenharia Química, Universidade Estadual de Campinas, Campinas, 2016.

CAIXETA, D. S. Sanificantes químicos no controle de biofilmes formados por duas espécies de Pseudomonas em superfície de aço inoxidável. $75 f$. Dissertação (Mestrado em Microbiologia Agrícola) - Universidade Federal de Lavras, Lavras, 2008.

CASALINI, J. Biofilmes Microbianos na Indústria de Alimentos, Universidade Federal de Pelotas, 2008. Disponível em: https://quimicadealimentos.files.wordpress.com/2009/08/biofilmes-microbianos-naindustria-de-alimentos.pdf doi

ClutTERBUCK, A. L.; WOODS, E. J.; KNOTTENBELT, D. C.; CLEGG, P. D.; COCHRANE, C. A.; PERCIVAL, S. L. Biofilms and their relevance to veterinary medicine. Veterinary Microbiology, v. 121, n. 1-2, p. 1-17, 2007. DOI: 10.1016/j.vetmic.2006.12.029 url

CODEX ALIMENTARIUS. Codex Alimentarius. 2019. Disponível: http://www.fao.org/fao-who-codexalimentarius/about-codex/en. Acesso em: 30 set. 2019.

EHLING-SCHULZ, M.; FRICKER, M.; SCHERER, S. Food-bacteria interplay: pathometabolism of emetic Bacillus cereus. Molecular Nutrition \& Food Research, v.48, p.479-487, 2004. DOI: 10.3389/fmicb.2015.00704. url

FLEMMING, H.C.; WINGENDER, J. 2010. The Biofilm Matrix. Nature Reviews Microbiology, 8, 623-633. http://dx.doi.org/10.1038/nrmicro2415

GARCIA, K. C. O. D. Utilização de bacteriófagos ambientais no controle de biofilmes de Salmonella spp. em superfícies na indústria de processamento e comercialização de carcaças de frango de corte e derivados. 2015, 43p. Dissertação (Mestrado em Medicina Veterinária) - Faculdade de Medicina Veterinária e Zootecnia, Campus de Botucatu, Universidade Estadual Paulista, 
Botucatu.

$43 p$,

2015.

Disponível

em:

https://repositorio.unesp.br/handle/11449/132128

GONÇALVES, A. I. D. Caracterização de biofilmes de estirpes persistentes de Listeria monocytogenes. Dissertação (Mestrado em Engenharia Alimentar). Universidade de Lisboa, 2017. Disponível em: https://www.repository.utl.pt/handle/10400.5/13853

GOMES, D.O. Estudo da produção de biofilme de isolados de Leptospira spp. 63 f. Tese (Mestre em Ciências Veterinárias) - Faculdade de Medicina Veterinária da UFU. Universidade Federal de Uberlândia, Uberlândia. 2016. Disponível em: https://repositorio.ufu.br/handle/123456789/13146?mode=full

GUTIÉRREZ D.;RODRÍGUEZ-RUBIO L., MARTÍNEZ B.; RODRÍGUEZ A.; GARCÍA $P$. Bacteriophages as weapons against bacterial biofilms in the food industry. Frontiers in microbiology, v. 7, p. 825, 2016. Disponível em: https://www.ncbi.nlm.nih.gov/pmc/articles/PMC4897796/ doi

IST. Grupo de Ciências Biológicas do Instituto Superior Técnico. Universidade Técnica de Lisboa. Crescimento microbiano em biofilmes. Publicado em 18/11/2005, Revisto em 10/04/2008. Disponível em < http://www.eescola.pt/topico.asp?id=354>. Acesso em: 30 set. 2019.

JAY, J.M. Biofilmes. In: Microbiologia de Alimentos. Porto Alegre: Artmed. 6ed., p.673-674, 711p. 2005.

JAHID, I.K.; HA, S.D. A review of microbial biofilms of produce: future challenge to food safety. Food Science and Biotechnology, v.21, p. 299-316, 2012. Disponível em:https://www.academia.edu/1959471/A_review_of_microbial_biofilms_of_produce _Future_challenge_to_food_safety doi

JIANG, T.; LI, M. Quorum sensing inhibitors: a patent review. Expert Opinion on Therapeutic Patents. v. 23. N. 7. p. 867-95. 2014. DOI:10.1080/13543776.2018.1541174 url

KUMARI, S.; SARKAR, P. K. Bacillus cereus hazard and control in indústrial dairy processing environment. Food Control, v. 69, p. 20-29, 2016. DOI: 10.1016/j.foodcont.2016.04.012 url

LALAWMPUII, H., \& CHATLI, M. K. . Battling biofilms. Dairy Industries International, 82(10), 36-39. 2017.

LASA, I. Towards the identification of the common features of bacterial biofilm development. International Microbiology, Barcelona, v.9, p.21-28, 2006. Disponível em:http://scielo.isciii.es/scielo.php?script=sci_abstract\&pid=\$1139670920060001000 03\&lng=en\&nrm=iso\&tlng=es doi

MARQUEZINE, M. G. Avaliação da capacidade de produção de biofilmes e detecção da enzima KPC em Salmonella spp. isolada de aviário e linha de 
abate de aves. Dissertação (Mestrado em Ciência e Tecnologia de Alimentos. Universidade de São Paulo, Piracicaba, 2015. f?

MARTINIS, E. C. P. Current knowledge and perspectives on biofilm formation: the case of Listeria monocytogenes. Applied Microbiology and Biotechnology, 2012. DOI: $10.1007 / \mathrm{s} 00253-012-4611-1$ url

MAJED, R.; FAILLE, C.; KALLASSY, M.; GOHAR, M. Bacillus cereus Biofilms Same, Only Different. Frontiers in Microbiology, v. 7, 2016. DOI: https://doi.org/10.3389/fmicb.2016.01054 url

MIAO J, LIN S, SOTEYOME T, PETERS B.M, LI Y, et al., Formation and development of Staphylococcus biofilm: with focus on food safety. Journal of food Safety, v. 37, n. 4, p. e12358, 2017. DOI: 10.1038/s41598-018-35558-2

MILLEZI, A.F. Ação de óleos essenciais sobre biofilmes formados por Staphylococcus aureus e Escherichia coli. 2012, 112p. Tese (Doutorado em Microbiologia de Alimentos) - Universidade Federal de Lavras, Lavras. 112p, 2012.

MUCKE, N. Sensibilidade celular e de biofilme de Enterococcus sp. aos desinfetantes de uso industrial. 2016. Dissertação de Mestrado. Universidade Tecnológica Federal do Paraná. p.?

OLIVEIRA, A.B.A. Doenças transmitidas por alimentos, principais agentes etiológicos e aspectos gerais: uma revisão. Porto Alegre-RS, 2010a.

OLIVEIRA' M. M.M; BRUGNERA D.F; ALVES E.; PICCOLI R.H. Biofilm formation by Listeria monocytogenes on stainless steel surface and biotransfer potential. Brazilian Journal Microbiology. 2010b; DOI: http://dx.doi.org/10.1590/S151783822010000100016

PEREIRA, A. A. Estudo da atividade bactericida de óleos essenciais sobre células planctônicas e sésseis de Salmonella spp. 2014, 94p. Tese (Doutorado em Microbiologia Agrícola) - Universidade Federal de Lavras, Lavras, 94p. 2014.

PIRES, A. C. S.; ARAÚJO, E. A.; CAMILLOTO, G. P.; RIBEIRO, M. C. T.; SOARES, N. F.F. et al. Condições higiênicas de fatiadores de frios avaliadas por ATPBioluminescência e contagem microbiana: sugestão de higienização conforme RDC 275 da ANVISA. Alimentos e Nutrição Araraquara. 2005.

REIS-TEIXEIRA, F. B.; ALVES, V. F.; MARTINS, E. C. P. Growth, viability anda architecture of biofilms of Listeria monocytogenes formed on abiotic surfaces. Brazilian Journal of Microbiology. 48:587-591, 2017. DOI: 10.1016/j.bjm.2017.01.004 url

SALDANHA, J.T.; Emprego de nanopartículas em estratégias de prevenção e tratamento de infecções relacionadas à formação de biofilmes bacterianos 
.Dissertação, Instituto Federal de Educação, Ciência e Tecnologia do Rio de Janeiro, Rio de janeiro, Set. 2014.

SILVA, J.; SILVA, M.; NASCIMENTO, G.; PEREIRA, D.; COSTA, C. Incidência de doenças transmitidas por alimentos (DTA) no estado de Pernambuco, um acompanhamento dos dados epidemiológicos nos últimos anos. Caderno de Graduação, v.3, p. 23-24, 2017.

SILVA, H. Avaliação da eficiência de diferentes desinfetantes sobre biofilmes de Bacillus Cereus em superfícies de aço inoxidável. Dissertação (Doutorado em Medicina Veterinária Preventiva). Universidade Estadual Paulista, 2017.

SIMÕES, M.; SIMÕES, L. C.; VIEIRA, M. J. A review of current and emergent biofilm control strategies. LWT - Food Science and Technology, v. 43, p. 573-583, 2010. Disponível em: www.innocua.net > web > download-1051 > simoes-lwt

SINGH, A.; WEESE, J. S.; ROUSSEAU, J.; WALKER, M. Characterization of the biofilm forming ability of Staphylococcus pseudintermedius from dogs. BMC Veterinary Research, v. 9, n.1, p. 93, 2014. DOI: 10.1186/1746-6148-9-93.

SOUZA, E. L.; MEIRA, Q. G. S.; DE MEDEIROS BARBOSA, I.; ATHAYDE, A. J. A. A.; DA CONCEIÇÃO, M. L.; DE SIQUEIRA JÚNIOR, J. P. Biofilm formation by Staphylococcus aureus from food contact surfaces in a meat-based broth and sensitivity to sanitizers. Brazilian Journal of Microbiology, v.45, p. 67-75, 2014. DOI: $10.1590 / \mathrm{s} 1517-83822014000100010$

SREY, S.; JAHID, I.K.; HÁ, S.D. Biofilm formation in food industries: A food safety concern. Food Control, v. 31, p.572-585, 2018. DOI: 10.3389/fmicb.2018.00898. url

TEIXEIRA, P.; RODRIGUES, D.; ROMEU, M.J.; AZEVEDO, J.; O impacto de biofilmes microbianos na higiene e segurança alimentar. Boletim de Biotecnologia, Braga, p. 31-34, 20 abr. 2015. doi; url

TONDO, E.C. Microbiologia e sistemas de gestão da segurança de alimentos. Porto Alegre: Sulina, 2019.???? incompleto

WANG H., YE. K.; WEI. X.; CAO. J.; XU. X. et al., Occurrence antimicrobial resistance and biofilm formation of Salmonella isolates from a chicken slaughter plant in China. Food Control, v. 33, n. 2, p. 378-384, 2014. DOI: 10.1016/j.foodcont.2013.03.030 url

YORK, A.Host response: fungal safeguards in the gut. Nature Reviews Microbiology, 16(1), 1. PMid:29217846. http://dx.doi.org/10.1038/nrmicro.2017. p. 155, 2017. DOI: http://dx.doi.org/10.1590/1981-6723.14418 